\title{
Characteristics of flow over the free overfall of triangular channel
}

\author{
Raad Irzooki ${ }^{1, *}$, Safa Hasan ${ }^{2}$ \\ ${ }^{1}$ Environmental Engineering Department, Tikrit University, Tikrit, Iraq \\ ${ }^{2}$ Civil Engineering Department, Tikrit University, Tikrit, Iraq
}

\begin{abstract}
In the present paper, the effects of side slopes, bed slopes and bed roughness on the flow over free overfalls in triangular channels have been studied experimentally. For this purpose, three models of triangular channels with free overfalls have been constructed and fixed in a $6 \mathrm{~m}$ length laboratory flume. These three models had length of $244 \mathrm{~cm}$ with different values of side slopes $(\mathrm{Z})(0.8(\mathrm{H}): 1(\mathrm{~V}), 1: 1$ and 1.33:1). Each one of these models had four different bed slopes (S) $(0,0.0041,0.0082$ and 0.0123$)$. For each bed slope, the bed was roughened with three particle sizes of sand (ds) $(1.18 \mathrm{~mm}, 2.36 \mathrm{~mm}$, and $4.75 \mathrm{~mm}$ ). The experimental testing program included sixteen series of experiments for each model. Four of them were for smooth beds and twelve for rough beds. A total of forty eight experiments were tested for different rates of discharge (Q). Experimental results of all models showed that Froude number $\left(\mathrm{Fr}_{b}\right)$ of flow decreases with the increasing of end depth ratio values $\left(\mathrm{yb}_{\mathrm{b}} / \mathrm{y}_{\mathrm{c}}\right)$ for different bed roughness, different bed slopes. The relations between the brink depth $\left(\mathrm{y}_{\mathrm{b}}\right)$ and the critical depth $\left(\mathrm{y}_{\mathrm{c}}\right)$ were found to be a simple linear formula for various bottom slope and different bottom roughness. An empirical expression was obtained for the flow over the free overfall in triangular channels for different bed slopes and roughness. The results of the present study have been compared with studies were obtained by other investigators, the comparison shows a very good agreement between them.
\end{abstract}

\section{Introduction}

The overfall is a weir with broad crest causing sudden change in water depth by free fall of water [1]. Studying the free overfall is important in hydraulic structures subject because of the possibility of using this structure in measuring the discharge in the laboratory in addition to its main function as a device to transport the flow from high level to lower level. The overfall structures can be shown permanently in natural or artificial channels. In natural channels the overfall formed by changing river bed level from a high level to a lower level as a result of erosion of the river bed, but in the artificial channels these structures can be formed by changing the bottom level of these channels for energy dissipation purposes.

Many experimental and theoretical researches were conducted to study the water overfalls. Rouse, 1936, is the first which pointed out the possibility of using the free overfall as a simple structure for measuring the discharge without requiring any calibration [2]. He found that the end depth ratio (EDR) for critical flow in rectangular and horizontal free overfall channel equal to 0.715. The end depth ratio is the ratio of end depth (bring depth) (yb) to the critical depth (yc). Also, Rouse proposed an empirical equation to measure the rate of discharge over free overfall of rectangular channel with Froud Number (Fr) ranging between 1 and 20. The researchers Delleur et al. presented a similar study on a rectangular channel, but with greater values of roughness. The results of this study show that the relative roughness $(\mathrm{ks} / \mathrm{yc}$ ) less than 0.1 (where ks represents height of roughnes) [3]. Also, Delleur's et al. study shows that when the value of $(\mathrm{ks} / \mathrm{yc})$ more than 0.1 , the EDR value will be smaller than the expected value due to the effect of roughness. (Rajaratnam et al., 1964) [4] present an experimental study on the various shapes of channels sections, they found that the value of the EDR is equal to 0.715 for confined rectangular channels, and for unconfined channels it is equal to 0.705. Also, they obtained that EDR equal to 0.795 for unconfined triangular channels. (Ali and Sykes, 1972)[5] and (Ahmad, 2002)[6] found that (EDR) for the triangular channel equal to 0.795 and 0.762 , respectively. (Ramamurthy et al., 2004)[7] studied the pressure head, flow velocity and water surface profile for trapezoidal free overfall channel. (Beirami et al., 2006)[8] presented theoretical study for different free overfall channel sections with horizontal slopes by using momentum equation. He found that the end depth ratio

\footnotetext{
* Corresponding author: dr.raadhoobi@tu.edu.iq
} 
(EDR) for rectangular, triangular and parabola channels sections equal to $0.7016,0.8051$ and 0.7642 , respectively, and indicated in this study that (Andersn, 1967)[9] and (Murty, 1994)[10] found (EDR) equal to 0.694 and 0.705 for the rectangular channels, 0.762 and 0.795 for the triangular channels and 0.735 and 0.758 for the channels parabola, respectively. (Gue et al., 2008)[11] investigated the channel bed roughness and bed slope effects on the flow over rectangular free overfall. In this study the bed was roughened by discrete square cross section strips with dimensions $(6 \mathrm{~mm} \times 6 \mathrm{~mm})$ and various distances between these strips. This study concluded that EDR decreases with increasing the ratio of spacing to height of strips (L/h). (Tigrek et al., 2008)[12] studied, experimentally, the bed slope and Manning's coefficient effects on the properties of flow over rectangular free overfalls. They concluded that EDR increases with increase in the roughness for any bed slope, also, EDR increases with decrease in the bed slope for both sub- critical and super-critical flow. (Mohammed et al., 2011)[13] studied the effect of bed roughness and bed slope in a rectangular overfall channel. Different bed roughness cases were used in this study with two bed slopes. They found six equations to evaluate EDR according to different bed roughness. (Ibrahim, 2016)[14] studied experimentally the bed roughness, side slope and bed slope effects on flow characteristics over free overfall trapezoidal channels. In this study, as done by Gue et al., 2008, the bed was roughened by square strips fixed at different spacing. This study shows that EDR decreases with increasing the bed slope and the average value of EDR is equal to 0.729 for sub-critical and super-critical flow with smooth bed.

The aim of the present study is to investigate the hydraulic characteristics of the free overfalls of the triangular channels with an indication of the influence of the channel bed roughness, longitudinal bed slope and side slope on the depth of water at the edge of overfall as well as the relationship of this depth with critical depth. Also, the present study aims to find empirical equation to calculate the discharge for the cases studied in this research.

\section{Dimensional analysis}

Dimensional analysis proves to be a generally valid method to recognize the information structure in the relationships between physical parameters in a precise and clear way. It starts from the fact that in quantitative natural science, the descriptive quantities have dimensions and can be divided correspondingly into basic quantities and derived quantities.

Dimensional analysis is helpful in laboratory work, because it provides a guide to those variables that significantly influence the phenomena; thus, it indicates the way in which experimental work should progress [15].

In this study a dimensional analysis was applied to predict an empirical equation for measuring the flow discharge over the free overfall of triangular channels as shown in Figure (1).
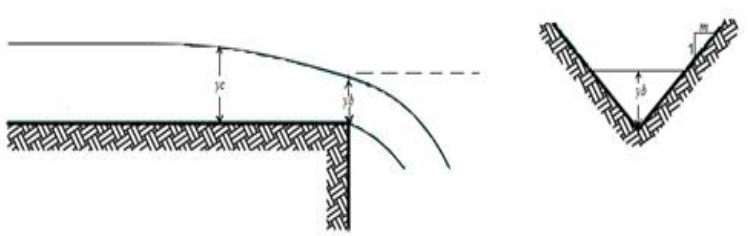

Fig. 1. Free overfall for triangular channel.

The possible factors influencing the flow discharge (Q) over free overfall are:

$Q=f_{1}\left(y_{b}, y_{c}, S, m, N, g, \rho, \mu\right)$

$\mathrm{Q}=$ Average flow discharge $\left(\mathrm{L}^{3} \mathrm{~T}^{-1}\right)$

$\mathrm{y}_{\mathrm{b}}=$ Bring depth $(\mathrm{L})$

$\mathrm{y}_{\mathrm{c}}=$ Critical depth $(\mathrm{L})$

$\mathrm{S}=$ Longitudinal slope of the channel

$\mathrm{m}=$ Side slope of the channel ( $\mathrm{m}$ (horizontal):1 (vertical))

$\mathrm{N}=$ Manning's roughness coefficient

$\mathrm{g}=$ Acceleration of gravity $\left(\mathrm{LT}^{-2}\right)$

$\rho=$ Mass density $\left(\mathrm{ML}^{-3}\right)$

$\mu=$ Water viscosity $\left(\mathrm{ML}^{-1} \mathrm{~T}^{-1}\right)$

Using Buckingham's Pi-theorem ( $\pi$ theorem), and choosing ( $\mathrm{y}_{\mathrm{b}}, \mathrm{g}$ and $\rho$ ) as repeated variables, the following equation of dimensionless parameters can be obtained:

$\frac{Q}{\sqrt{g y_{b}^{5}}}=f_{2}\left(\operatorname{Re}, \frac{y_{c}}{y_{b}}, S, N, m\right)$

As mentioned by Chow, 1959[16], when the flow is turbulent, the viscosity forces become weak relative to inertia forces, therefore, it can neglect Reynolds's number (Re). Rearranging Equation (2), the following equation can be obtained:

$\frac{Q}{\sqrt{g y_{b}^{5}}}=f_{3}\left(\frac{y_{c}}{y_{b}}, S, N, m\right)$

\section{Experimental work}

The experimental work of this study was carried out in Hydraulic laboratory at Environmental Engineering Department in Tikrit University. This work was conducted in $6 \mathrm{~m}$ long rectangular flume, with cross section of $0.3 \mathrm{~m}$ width and $0.4 \mathrm{~m}$ height. The walls of this flume is Perspex glass and the bed is painted iron. The models of triangular free overfall channel of each test were constructed using $6 \mathrm{~mm}$ thickness Perspex glass, these models were fixed in the working flume by adhesive material to prevent any leakage from sides and bottom. The experimental tests of this study were divided into three groups (A, B and C). Each group represents free overfall triangular channel with side slope, (m), 0.8:1, 1:1 and 1.33:1, respectively. The tests 
of each group were carried out with four different longitudinal slopes (S) (0 (horizontal slope), 1/244, $2 / 244$ and $3 / 244)$. For each of the above tests four different roughness $(\mathrm{N})$ of the channel sides were used, the first one is without using any roughing material on the channel sides, and in the other three types the channel sides were roughened by using three different sizes of gravel $(1.18,2.36$ and $4.75 \mathrm{~mm})$. For each run, eight different discharges (at least) were passed, therefore 425 runs were carried out in this study.

The discharge which passes through the channel was measured by using 90o V-notch weir with sharp crest. This weir was manufactured from $10 \mathrm{~mm}$ thickness Perspex glass. The flow rate passing over this weir was calculated using the volumetric method, where for each head above the weir crest, the discharge was measured three times and the rate of these discharges was calculated. Thus, the discharge equation for this weir was developed as follows:

$Q=0.012 H^{2.552}$

$Q=$ Rate of discharge $(\ell / \mathrm{sec})$

$H=$ Depth of water over the weir crest $(\mathrm{cm})$

Two point gauges with accurately reading of $0.1 \mathrm{~mm}$ were used for measuring the bring depth (yb) of the triangular overfall channel and the water depth over the weir crest. Figure (2) shows working flume with experimental setup details.

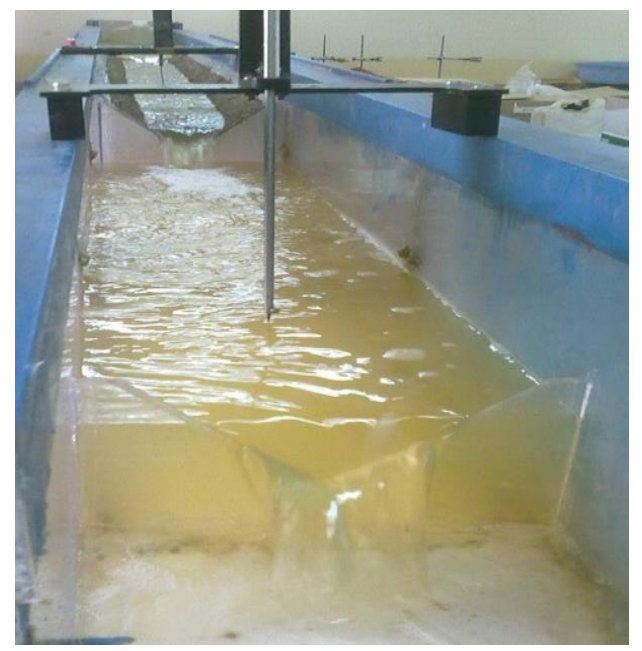

Fig. 2. Experimental flume with accessories.

The variables that were measured for each experiment are the water depth at the beginning of the channel $\left(\mathrm{y}_{\mathrm{n}}\right)$, the bring depth at the edge of the free overfall $\left(\mathrm{y}_{\mathrm{b}}\right)$ and the depth of water above the triangle weir $(H)$. The critical depth $\left(\mathrm{y}_{\mathrm{c}}\right)$ for each test was calculated by the following equation:

$$
\frac{Q^{2}}{g}=\frac{A_{c}^{3}}{T_{c}}
$$

Where :

$A_{c}=$ The cross section area of flow at critical condition $T_{c}=$ Top width of water surface at critical condition

$$
\begin{gathered}
=2 m y_{c} \\
A_{c}=m y_{c}^{2} \\
T_{c}=2 m y_{c}
\end{gathered}
$$

Substituting Equations (6) and (7) in Equation (5), the following equation produced:

$$
y_{c}=\sqrt[5]{\frac{2 Q^{2}}{g m^{2}}}
$$

\section{Results and discussion}

The experimental results of this study were prepared according to parameters that were produced from dimensional analysis as mentioned in previous section.

\subsection{Relation of bring depth $\left(y_{b}\right)$ with critical depth $\left(y_{c}\right)$}

Figures (3, 4, 5 and 6) show the relationship between the bring depth $\left(\mathrm{y}_{\mathrm{b}}\right)$ and the critical depth $\left(\mathrm{y}_{\mathrm{c}}\right)$ for $(\mathrm{m} 1)$ triangular channel free overfall with various bottom slope and different bottom roughness. It can be seen that this relation is defined as simple linear formula as follows:

$$
y_{b}=a_{1}\left(y_{c}\right)
$$

From these figures it can be seen that $\left(\mathrm{y}_{\mathrm{b}}\right)$ increases with increase in $\left(\mathrm{y}_{\mathrm{c}}\right)$ at a high correlation coefficient for the sub-critical and super-critical flow conditions, as shown in Table (1).

N0 means the bed of the channel without using any roughing material, and $\mathrm{N} 1, \mathrm{~N} 2, \mathrm{~N} 3$ represent the bed roughness with using gravel of size 1.18, 2.36 and $4.75 \mathrm{~mm}$, respectively. S0 refers to horizontal bed slope and S1, S2, S3 represent bed slope of the triangular channel equal to $(1 / 244=0.0041),(2 / 244=0.0082)$ and $(3 / 244=0.00123)$, respectively.

Also, the above figures show that the bed slope and bed roughness have a slight effect on the relation between the bring depth and the critical depth. It is worth to mention that same results were produced for the channels with side slopes ( $\mathrm{m} 2$ and $\mathrm{m} 3$ ).

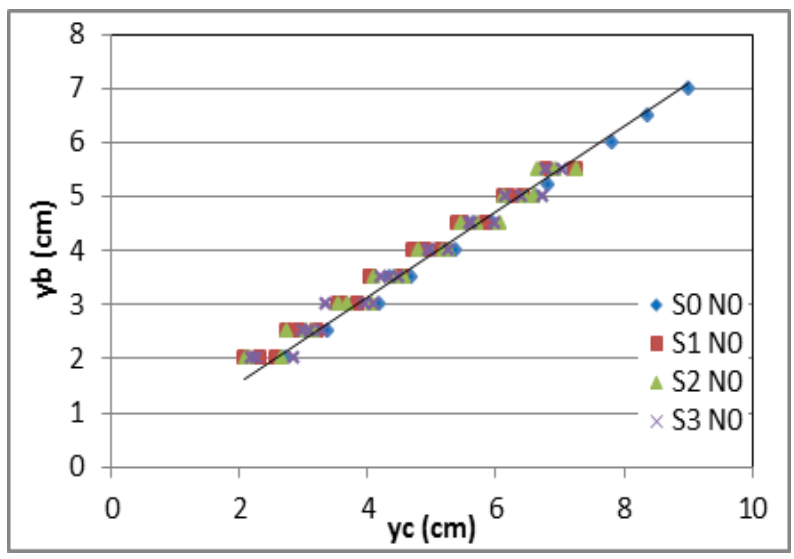

Fig. 3. Variation of $\left(\mathrm{y}_{\mathrm{b}}\right)$ with $\left(\mathrm{y}_{\mathrm{c}}\right)$ for triangular channels without roughness material and different bed slopes. 


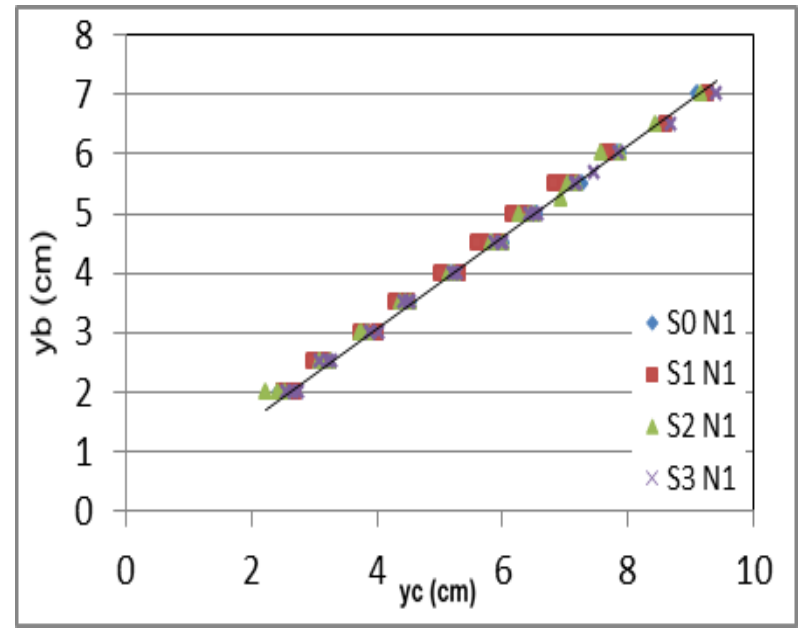

Fig. 4. Variation of $\left(\mathrm{y}_{\mathrm{b}}\right)$ with $\left(\mathrm{y}_{\mathrm{c}}\right)$ for triangular channels with N1 roughness material and different bed slopes.

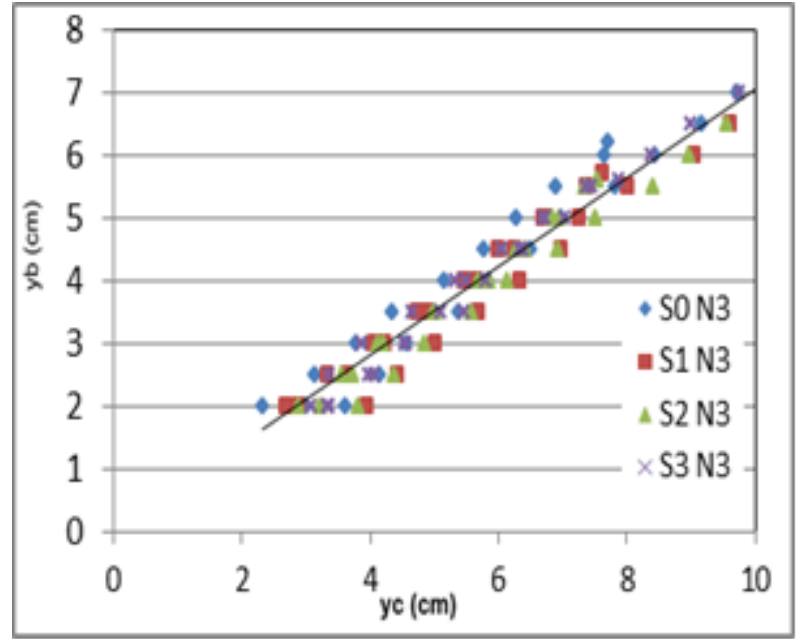

Fig. 5. Variation of $\left(\mathrm{y}_{\mathrm{b}}\right)$ with $\left(\mathrm{y}_{\mathrm{c}}\right)$ for triangular channels with N2 roughness material and different bed slopes.

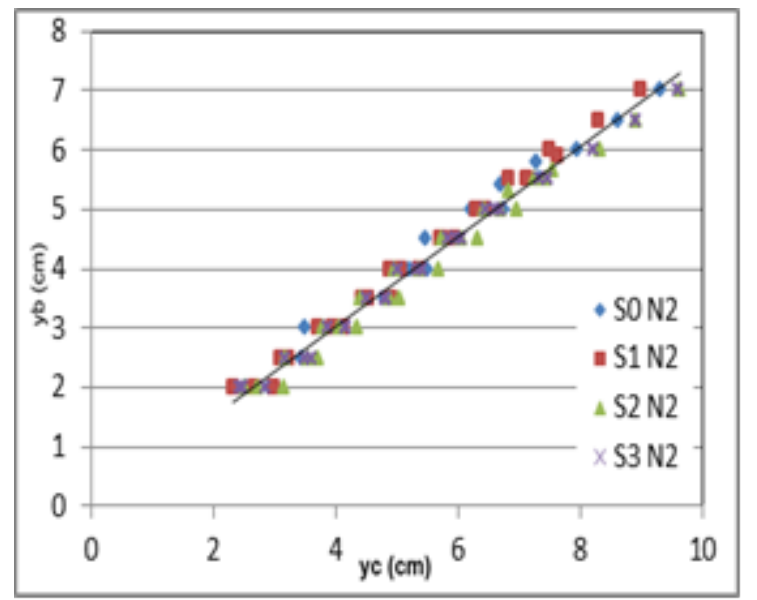

Fig. 6. Variation of $\left(\mathrm{yb}_{\mathrm{b}}\right)$ with $\left(\mathrm{y}_{\mathrm{c}}\right)$ for triangular channels with $\mathrm{N} 3$ roughness material and different bed slopes.
Table 1. Magnitudes of (a1) constant and determination coefficients for triangular channels different bed roughness and different bed slopes.

\begin{tabular}{|c|c|c|c|}
\hline Roughness & $\mathrm{a}_{1}=(\mathrm{yb} / \mathrm{yc})$ & $\mathrm{R}^{2}$ & $\mathrm{Fr}$ \\
\hline $\mathrm{N} 0$ & 0.788 & 0.978 & $0.45-1.47$ \\
\hline $\mathrm{N} 1$ & 0.7704 & 0.995 & $0.44-1.13$ \\
\hline $\mathrm{N} 2$ & 0.7577 & 0.983 & $0.32-1.00$ \\
\hline $\mathrm{N} 3$ & 0.7048 & 0.955 & $0.31-0.94$ \\
\hline
\end{tabular}

\subsection{Relationship of $\left(Q / \sqrt{g y_{b}^{5}}\right)$ with $\left(y_{b} / y_{c}\right)$}

The dimensionless parameter $\left(Q / \sqrt{g y_{b}^{5}}\right)$ represents Froud Number $\left(\mathrm{Fr}_{\mathrm{b}}\right)$ of flow over free overfall triangular channel in terms of bring depth $\left(\mathrm{y}_{\mathrm{b}}\right)$. The variation of this parameter according to the ratio $\left(\mathrm{y}_{\mathrm{b}} / \mathrm{y}_{\mathrm{c}}\right)$ was studied for different bed roughness and for all cases of bed slope that were investigated in this study. Figures (7, 8 and 9) show the relation of the parameter $\left(Q / \sqrt{g y_{b}^{5}}\right)$ or $\left(\mathrm{Fr}_{\mathrm{b}}\right)$ with the ratio $\left(\mathrm{y}_{\mathrm{b}} / \mathrm{y}_{\mathrm{c}}\right)$ for different bed roughness and $\mathrm{S} 1$ bed slope of triangular channel with side slope $(\mathrm{m} 1, \mathrm{~m} 2$ and $\mathrm{m} 3$ ), respectively.

Same relations were observed channels with bed slope S2 and S3.

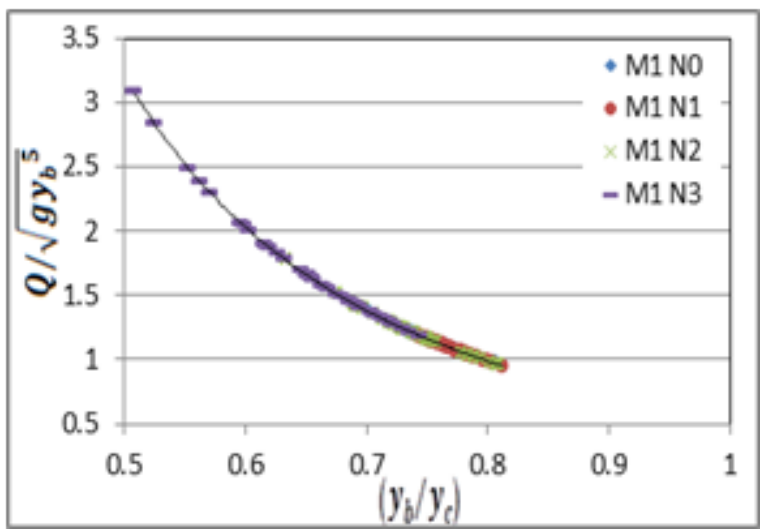

Fig.7. Variation of $\left(Q / \sqrt{g y_{b}^{5}}\right)$ with $\left(\mathrm{y}_{\mathrm{b}} / \mathrm{y}_{\mathrm{c}}\right)$ for triangular channels with $\mathrm{m} 1$ side slope, $\mathrm{S} 1$ bed slope and different roughness material. 


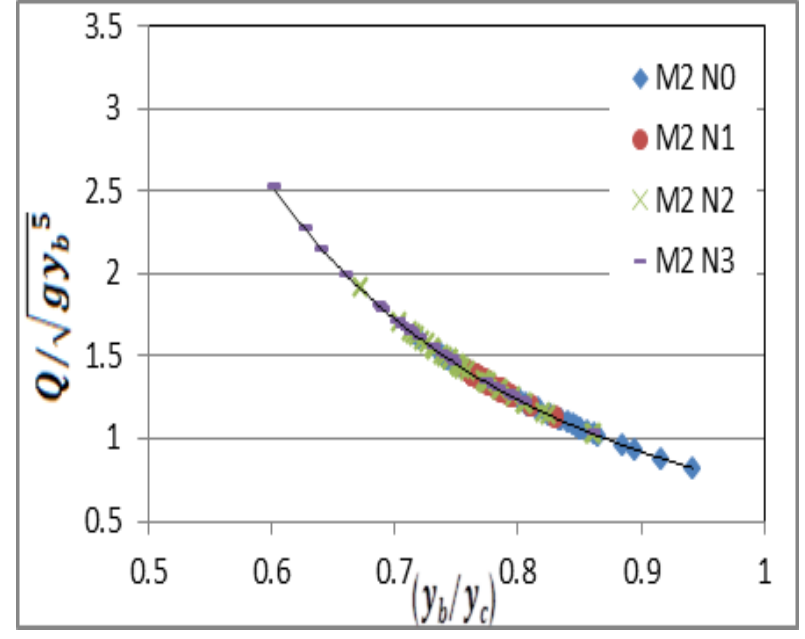

Fig. 8. Variation of $\left(Q / \sqrt{g y_{b}^{5}}\right)$ with $\left(\mathrm{y}_{\mathrm{b}} / \mathrm{y}_{\mathrm{c}}\right)$ for triangular channels with $\mathrm{m} 2$ side slope, $\mathrm{S} 1$ bed slope and different roughness material.

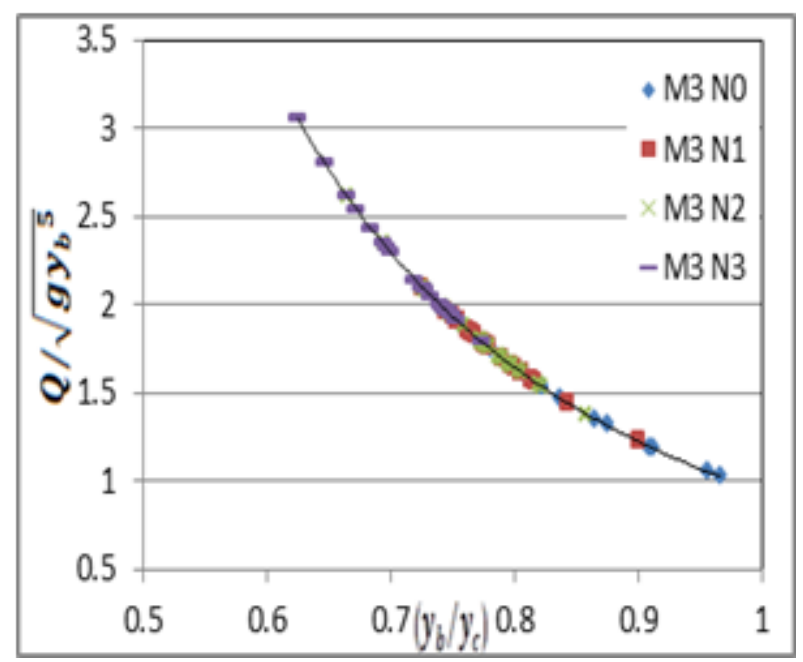

Fig. 9. Variation of $\left(Q / \sqrt{g y_{b}^{5}}\right)$ with $\left(\mathrm{y}_{\mathrm{b}} / \mathrm{y}_{\mathrm{c}}\right)$ for triangular channels with $\mathrm{m} 3$ side slope, $\mathrm{S} 1$ bed slope and different roughness material.

From these figures it can be seen that $\left(\mathrm{Fr}_{\mathrm{b}}\right)$ decreases with increase in the end depth ratio $\left(\mathrm{y}_{\mathrm{b}} / \mathrm{y}_{\mathrm{c}}\right)$. Also, these figures show that the variation of the side slope effects on the relation between $\left(\mathrm{Fr}_{\mathrm{b}}\right)$ and $\left(\mathrm{y}_{\mathrm{b}} / \mathrm{y}_{\mathrm{c}}\right)$, where, for constant $\left(\mathrm{Fr}_{\mathrm{b}}\right)$ the end depth ratio $\left(\mathrm{y}_{\mathrm{b}} / \mathrm{y}_{\mathrm{c}}\right)$ increases with increase in $(\mathrm{m})$ (which means decreasing the inclination of the channel sides with the horizontal). In addition to the above, the bed roughness and bed slope of the channel was found to have no or very little effect on this relation for all conditions of flow.

\section{Discharge equation of triangular channel with free overfall}

The experimental data were used to produce an empirical equation for measuring the discharge through triangular channel with free overfall, where approximately $70 \%$ of these data can be expressed in to following equation by using a statistical program SPSS 19.
$Q=1.252 g^{0.5} m y_{b}^{2.5} \frac{S^{0.01}}{N^{0.047}}$

The coefficient of determination of this equation (R2) equal to 0.922 .

This equation clearly shows that the influence of bed slope $(\mathrm{S})$ and bed roughness $(\mathrm{N})$ is relatively small on the discharge. This agrees with the analysis of the above results, where these results show that no or little influence of the bed slope and bed roughness on the Froud Number, which is the same on the discharge. The magnitude of the parameter $\left(\frac{S^{0.1}}{N^{0.047}}\right)$ is approximately equal to unity, therefore, Equation (10) can be reduced to a final form as follows:

$Q=1.252 g^{0.5} m y_{b}^{2.5}$

The remaining approximately $30 \%$ of the experimental data were used to verify the above developed equation. Figure (10) represents the relation between the resulted experimental discharges for different cases of triangular channel with free overfall and the discharges were measured from Equation (11) for the same conditions of these cases. This figure and the calculated standard error ratio for this relation, which is equal to $0.154 \%$, show a good agreement between the experimental and measured results.

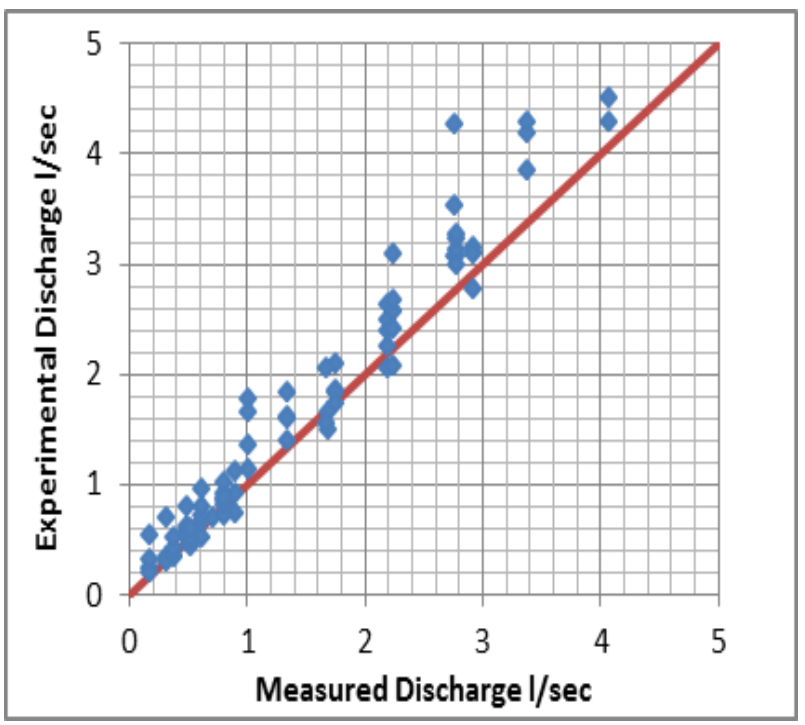

Fig. 10. The relation between experimental discharge and calculated discharge by Equation (11) for triangular channels overfalls.

Also, the observed equation of this study coincides with relations that were derived by earlier researchers, for horizontal channels without roughness material, as shown in Table (2). Figure (11) represents the relation between the calculated discharge and bring depth for triangular channel free overfall with side slope (m1) using the different observed equations. 
Table 2. Observed equations for flow over triangular channel free overfall.

\begin{tabular}{|c|c|c|}
\hline Researchers & Equation & $\begin{array}{c}\text { Différence } \\
\text { Ratio \% }\end{array}$ \\
\hline $\begin{array}{c}\text { Rajaratnam and } \\
\text { Muralidhar, } 1964\end{array}$ & $Q=1.2548 g^{95} m_{b}^{2 x}$ & 0.0255 \\
\hline Andersen, 1967 & $Q=1.395 g^{05}$ myb $^{28}$ & 1.2096 \\
\hline Ali and Sykes, 1972 & $\mathrm{Q}=1.243 \mathrm{~g}^{\mathrm{as}} \mathrm{myb}^{2 \mathrm{~s}}$ & 0.0825 \\
\hline Murty, 1994 & $\mathrm{Q}=1.2548 \mathrm{~g}^{0 \mathrm{~s}} \mathrm{myb}^{2 . s}$ & 0.0255 \\
\hline Ahmad, 2002 & $\mathrm{Q}=1.2276 \mathrm{~g}^{0 \mathrm{~s}} \mathrm{my}_{\mathrm{b}} \mathrm{ns}$ & 0.2258 \\
\hline Beirami et al., 2006 & $\mathrm{Q}=1.2158 \mathrm{~g}^{205} \mathrm{myb}^{2 . s}$ & 0.3372 \\
\hline The present study & $\mathrm{Q}=1.252 \mathrm{~g}^{0 \mathrm{~s}} \mathrm{myb}_{\mathrm{b}}{ }^{2 \mathrm{~s}}$ & - \\
\hline
\end{tabular}

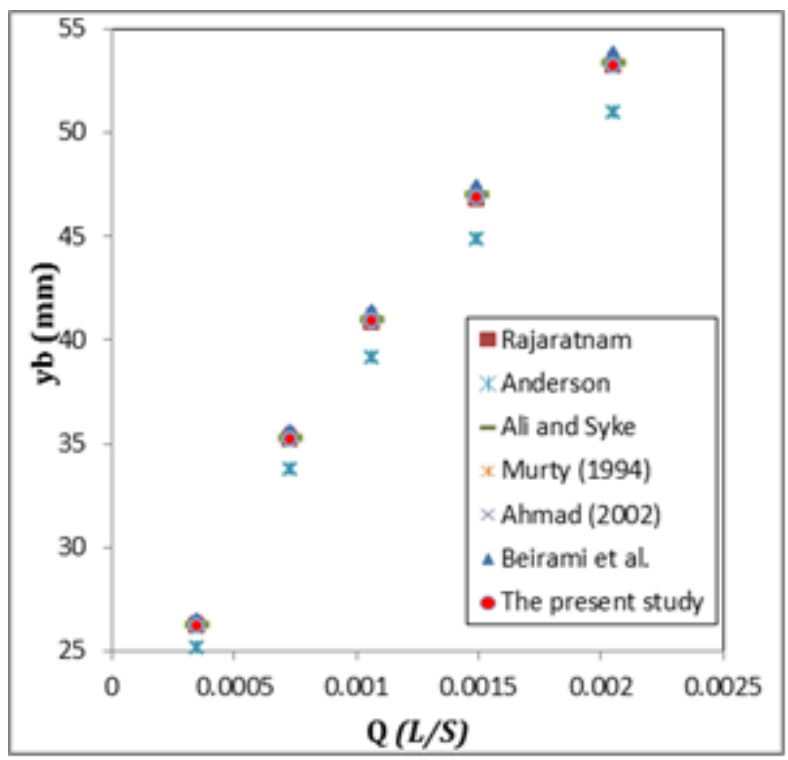

Fig. 11. Comparison of present study with earlier researches.

\section{Conclusions}

In the present study, the characteristics of flow in triangular channels with free overfalls were experimentally examined. The experiments were carried out by passing different discharges through channels with different bed slope, side slopes and bed roughness.

Based on the analysis of the resulting data for 425 tests, the following points represent the main conclusions of this study:

1- The bring depth $\left(\mathrm{y}_{\mathrm{b}}\right)$ increases with increase in the critical depth $\left(\mathrm{y}_{\mathrm{c}}\right)$, and the average end depth ratio (EDR) or $\left(\mathrm{y}_{\mathrm{b}} / \mathrm{y}_{\mathrm{c}}\right)$ was found equal to 0.755 .

2- Froud Number $\left(\mathrm{Fr}_{\mathrm{b}}\right)$ decreases with increase in the end depth ratio $\left(\mathrm{y}_{\mathrm{b}} / \mathrm{y}_{\mathrm{c}}\right)$ and this relation is affected by variation in the side slope of the triangular channel, where the same Froud Number, the EDR increases with increase in the magnitude of $(\mathrm{m})$ from 0.8 to 1.33 .
3- The bed roughness and bed slope of the channel was found to have no or very little effect on the relation between $\left(\mathrm{Fr}_{\mathrm{b}}\right)$ and EDR.

4- A good equation was developed for measuring the discharge through triangular channel with free overfall.

\section{References}

1. A. Y. Mohammed, Journal of Al-Rafidain Engineering 17, 1, (2009).

2. H. Rousel, Civil Engineering 6, 4, 257-260 (1936).

3. J. W. Delleur, J. C. I. Dodge, and K. N. Gent, Journal of Hydraulic Division, ASCE 82, 4 (1956).

4. N. Rajaratnam, and D. Muralidhar, Journal of Hydraulic Division, ASCE 90,1, (1964).

5. K. H. M. Ali, and A. Sykes, Journal of Hydraulic Division, ASCE 98, 5 (1972).

6. Z. Ahmad, Conf. of Hyd., Water Resources and Ocean Eng., 115-119 (2002).

7. A. S. Ramamurthy, C. Zhai, and J. Qu, Journal of Irrigation and Drainage Engineering, ASCE 130, 5 (2004).

8. M. K. Beirami, S. V. Nabavi, and M. R. Chamani, Iranian Journal of Science and Technology, Transaction B, Engineering 30, No. B1 (2006).

9. M. V. Andersen, Acta Polytechnica Scandinavica 42, 1-24 (1967)

10. B. S. Murty, J. Hydr. Res. 32, 2, 219-232 (1994).

11. Y. Gue, L. Zhang, Y. Shen, and J. Zhang, Journal Hydraulic Engineering, ASCE 134, 5 (2008).

12. S. Tigrek, C. E. Firat and A. M. Ger, Journal of Irrigation and Drainage Engineering, ASCE 134, 89 (2008).

13. M. Y. Mohammed, A. Y. Al-Taee, and A. N. AlTalib, Damascus University Journal 27, 1 (2011).

14. S. S, Ibrahim and B. M. A. Noori, ZANCO 28, 2, 127-136 (2016).

15. M. H. Chaudhry, Open Channel Flow, 2nd ed. Springer Science and Business Media, LLC, New York (2008).

16. V. T. Chow, Open-Channel Hydraulics, International Edition, McGraw-Hill, (1959). 